\title{
EFECTO ANTIIFLAMATORIO DE LA FRACCIÓN FLAVONOIDE DE Lepechinia meyenii (Walp.) Epling (SALVIA) SOBRE LEUCOCITOS DE PACIENTES CON ARTRITIS REUMATOIDE
}

\author{
Carlos Alberto Arenas-Chavez $z^{1,2, a}$, Tomas Wiche-Salinas ${ }^{1, b}$, Ignacio Valencia-Mercado ${ }^{1, b}$, Ronald Calle-Valdez ${ }^{1, b}$, \\ Corina Vera-Gonzales $^{3, \mathrm{~d}}$, Stephanie Malaga-Contreras ${ }^{1, \mathrm{e}}$, Fernando Flores-Rivera $^{1, \mathrm{e}}$, Carlos Huanqui-Guerra ${ }^{1, \mathrm{f}}$
}

\begin{abstract}
RESUMEN
Objetivos. Evaluar el efecto antiinflamatorio de la fracción flavonoide de Lepechinia meyenii (Walp.) Epling sobre leucocitos de pacientes con artritis reumatoide (AR). Materiales y métodos. Se recolectaron plantas de la especie Lepechinia meyenii (Walp.) Epling extrayendo diferentes fracciones flavonoides por cromatografía de columna y de capa fina. Se evaluó la producción de anión superóxido mediante la técnica de ensayo reducción nitroblue tetrazolium, en neutrófilos obtenidos de

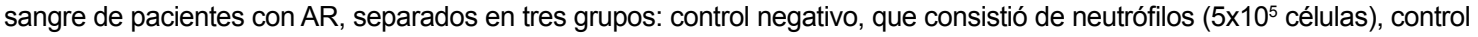
positivo, formado por neutrófilos activados con PMA (phorbol myristate acetate) $(150 \mathrm{ng} / \mathrm{mL}$ ) y los tratamientos, formados por neutrófilos activados y tratados con diferentes concentraciones de la fracción flavonoide LM8 (60, 120 y $180 \mathrm{ug} / \mathrm{mL})$. La expresión de genes proinflamatorios se estudió por RTqPCR, en leucocitos mononucleares obtenidos de pacientes con AR separados en tres grupos: control negativo, que consistió de leucocitos mononucleares ( $5 \times 10^{5}$ células), control positivo formado por leucocitos mononucleares activados con fitohemaglutinina (PHA) $(150 \mathrm{ug} / \mathrm{mL})$ y el tratamiento formado por leucocitos mononucleares activados y tratados con la fracción flavonoide LM8 $(120 \mathrm{ug} / \mathrm{mL})$. Resultados. Se purificaron varias fracciones flavonoides, resultando la fracción LM8 con el mejor efecto inmunomodulador. Dicha fracción disminuyó la producción de anión superóxido en una manera dependiente de la concentración. Por otro lado, disminuyó la expresión de TNFa, IL8 e IL17 en leucocitos mononucleares Conclusiones. Estos resultados son alentadores respecto al efecto inmunomodulador de esta planta medicinal peruana y justifican continuar su estudio para una posible aplicación clínica.
\end{abstract}

Palabras Claves: Leucocitos; Neutrófilos; Flavonoide; Inmunomodulador; Salvia; Artritis reumatoide. (fuente: DeCS BIREME).

\section{ANTI-INFLAMMATORY EFFECT OF THE FLAVONOID FRACTION OF Lepechinia meyenii (Walp.) Epling (SAGE) ON LEUKOCYTES OF PATIENTS WITH RHEUMATOID ARTHRITIS}

\begin{abstract}
Objectives. to assess the anti-inflammatory effect of the flavonoid fraction of Lepechinia meyenii (Walp.) Epling on leukocytes of patients with rheumatoid arthritis (RA). Materials and Methods. Plants of the species Lepechinia meyenii (Walp.) Epling were collected and then different flavonoid fractions were extracted by column and thin layer chromatography. The superoxide anion production was evaluated by means of the reduction of nitroblue tetrazolium assay technique in neutrophils obtained from the blood of patients with RA, divided into three groups: negative control, which consisted of neutrophils $\left(5 \times 10^{5}\right.$ cells); positive control, made up of PMA (phorbol myristate acetate)-activated neutrophils $(150 \mathrm{ng} / \mathrm{mL}$ ), and the treatments, comprised of neutrophils activated and treated with different concentrations of the flavonoid fraction LM8 $(60,120$, and $180 \mathrm{ug} / \mathrm{mL})$. The expression of proinflammatory genes was studied by RTqPCR in mononuclear leukocytes obtained from patients with RA, divided into three groups: negative control, which consisted of mononuclear leukocytes $\left(5 \times 10^{5}\right.$ cells); positive control, made up of phytohaemagglutinin (PHA) (150 ug/ml)-activated mononuclear leukocytes, and the treatment, comprised of mononuclear leukocytes activated and treated with the flavonoid fraction LM8 $(120 \mathrm{ug} / \mathrm{mL})$. Results. Several flavonoid fractions were purified, with fraction LM8 showing the best immunomodulating effect. Said fraction diminished the superoxide anion production dependent on concentration. On the other hand, it diminished the expression of TNFa, IL8, and IL17 in mononuclear leukocytes. Conclusions. These results are encouraging in terms of the immunomodulating effect of this Peruvian medicinal plant and justify the continuation of their study for a potential clinical application.
\end{abstract}

Keywords: Rheumatoid Arthritis; Salvia; leukocytes; Anion superoxide; Proinflammatory genes (source: MeSH NLM).

\footnotetext{
Facultad de Medicina Humana, Universidad Católica de Santa María. Arequipa, Perú.

Facultad de Ciencias Biólogicas, Universidad Nacional de San Agustin. Arequipa, Perú.

Facultad de Ciencias Naturales y Formales, Universidad Nacional de San Agustín. Arequipa, Perú.

M.Sc. en biologia molecular y biomedicina; ${ }^{\mathrm{b}}$ médico cirujano; ${ }^{\mathrm{d}}$ doctora en química; ${ }^{\mathrm{e}}$ estudiante medicina; ${ }^{\mathrm{f}}$ doctor en medicina

Recibido: 08/05/2017 Aprobado: 07/03/2018 En línea: 05/04/2018
}

Citar como: Arenas-Chavez CA, Wiche-Salinas T, Valencia-Mercado I, Calle-Valdez R, Vera-Gonzales C, Malaga-Contreras S, Huanqui-Guerra C. Efecto antiiflamatorio de la fracción flavonoide de Lepechinia meyenii (Walp.) Epling (Salvia) sobre leucocitos de pacientes con artritis reumatoide. Rev Peru Med Exp Salud Publica. 2018;35(1):55-61 doi: 10.17843/rpmesp.2018.351.3600. 


\section{INTRODUCCIÓN}

En la medicina tradicional son utilizadas diferentes especies del género Lepichinia, como antidiabético, emenagogo, abortivo y para el tratamiento de tumores uterinos ${ }^{(1)}$. En el caso de la especie Lepechinia meyeni (Walp.) es utilizada como digestivo, carminativo, para el tratamiento de bronquitis, alteración del ciclo menstrual y tratamiento de heridas ${ }^{(2,3)}$.

En esta especie se ha identificado compuestos polifenólicos como el carnosol, ácido ursólico, diosmetina, ácido cafeico y ácido 2-hidroxicafeico, reportándose una excelente actividad antioxidante debida principalmente al ácido 2-hidroxicafeico y al carnosol ${ }^{(4)}$.

Igualmente se ha identificado derivados de flavonas como naringenina, derivados de ácido hidroxicinamico como el ácido cumarico y ácido clorogénico, demostrándose que las hojas de L.meyeni tienen una elevada actividad antioxidante ${ }^{(5,6)}$

Los compuestos polifenólicos incluyen una gran variedad de flavonoides que son abundantes en frutas, verduras, semillas y bebidas (té y vinos) y son referidos como nutrientes semiesenciales en humanos. Los efectos beneficios de los flavonoides han sido atribuidos a sus propiedades antioxidantes y antinflamatorias ${ }^{(7)}$. Estudios epidemiológicos han demostrado que poblaciones que consumen alimentos ricos en polifenoles tienen baja incidencia de enfermedades inflamatorias ${ }^{(8)}$.

Una de las principales enfermedades que implica un proceso inflamatorio es la artritis reumatoide (AR) ${ }^{(9)}$ donde se ha descrito que hay una inflamación de la sinovia por los siguientes agentes: Macrófagos, que actúan mediante la secreción de citoquinas (Factor de Necrosis Tumoral alfa (TNFa), Interleucina 1, etc.), especies reactivas del oxígeno y de nitrógeno; derivados del ácido araquidónico, fagocitosis y presentación de antígenos ${ }^{\left({ }^{9}\right)}$. Otra célula muy importante son los linfocitos T colaboradores 17 (LTh17) un subtipo de linfocitos T que producen interleucina 17A (IL17A), 17F, 21, 22 y TNFa, contribuyendo con el proceso inflamatorio $(10,11)$. Por último, están los neutrófilos que favorecen a la sinovitis, por medio de producción de radicales libres, prostaglandinas y proteasas ${ }^{(12)}$.

En la actualidad el tratamiento de la AR implica el uso de anti-inflamatorios no esteroideos (AINE) inhibiendo la producción de prostaglandinas, el metrotexate disminuyendo la proliferación de leucocitos hasta la terapia biológica contra la IL1 y el TNFa ${ }^{(13,14)}$. Sin embargo, a pesar de las terapias que se tienen, muchos pacientes desarrollan complicaciones, por lo que es pertinente la búsqueda de nuevas formas de tratamiento ${ }^{(13,15-17)}$.

Un área de interés es la búsqueda de nuevas alternativas de tratamiento, mediante la investigación de principios

\section{MENSAJES CLAVE}

Motivación para realizar el estudio. Lepechinia meyenii también llamada salvia andina, podría tener efectos antiinflamatorios mediado por la regulacion de moléculas como las especies reactivas de oxígeno y genes proinflamatorios.

Principales hallazgos. La fracción flavonoide LM8 purificada a partir de Lepechinia meyenii tuvo un efecto antiinflamatorio, reduciendo la producción de anión superóxido en neutrófilos activados así como disminuyendo la expresión de citoquinas proinflamatorias tales como TNFa, IL8 e IL17 en leucocitos mononucleares de sangre periférica de pacientes con artritis reumatoidea.

Implicancias. El tratamiento de la artritis reumatoide implica el uso de anti-inflamatorios no esteroideos, a pesar de las terapias existentes muchos pacientes desarrollan complicaciones, por lo que es pertinente la búsqueda de nuevas formas de tratamiento para una posible aplicación clínica.

activos de diversas plantas que han demostrado tener efectividad in vitro como antioxidantes o disminuyendo la expresión génica de proteínas relacionadas a la patogénesis de la enfermedad ${ }^{(11,18,19)}$. El Perú posee una alta diversidad vegetal y representa una fuente importante para el descubrimiento de nuevas variedades de plantas para el tratamiento de AR, siendo una de ellas, Lepechinia meyenii (Walp.) Epling, también llamada salvia andina (20). Si bien, se ha reportado estudios sobre la composición química y actividad antioxidante de esta especie, existe escasa información del efecto antiinflamatorio mediado por la regulación de moleculas inflamatorios como las especies reactivas de oxígeno y genes proinflamatorios.

Considerando lo mencionado anteriormente, el objetivo del presente estudio fue determinar el efecto antiinflamatorio de la fracción flavonoide de Lepechinia meyenii (Walp.) Epling en leucocitos sanguíneos de pacientes con artritis reumatoide.

\section{MATERIALES Y MÉTODOS}

\section{DISEÑO DEL ESTUDIO}

Se recolectaron plantas de la especie Lepechinia meyenii (Walp.) Epling a partir de la cual se separaron diferentes fracciones flavonoides por cromatografía de columna y de capa fina, eligiendo a la fracción LM8 para realizar las pruebas de actividad biológica.

Para la evaluación de la producción de anión superóxido, se purificaron neutrófilos a partir de sangre entera de pacientes con artritis reumatoide, los cuales fueron separados en tres grupos: el control negativo, que consistió de neutrófilos ( $5 \times 10^{5}$ células/pozo), el control positivo formado por 
neutrófilos activados con PMA (phorbol myristate acetate) (150 ng/mL) y los tratamientos formados por neutrófilos activados y tratados con diferentes concentraciones de la fracción flavonoide LM8 $(60,120$ y 180 ug/mL).

Para la evaluación de la expresión génica de genes proinflamatorios, se realizó la purificación de leucocitosmononucleares a partir de sangre entera de pacientes con artritis reumatoide, las que fueron cultivadas en medio RPMI1640 y separados en tres grupos: un primer grupo control negativo que consistió de leucocitos mononucleares (5 × $10^{5}$ células/pozo), el control positivo formado por leucocitos mononucleares activados con fitohemaglutinina (150 ug/mL) y el tratamiento formado por leucocitos mononucleares activados y tratados con la fracción flavonoide LM8 a una concentración de 120 ug/mL.

\section{RECOLECCIÓN Y CLASIFICACIÓN TAXONÓMICA DE LA ESPECIE VEGETAL}

La especie fue obtenida del Centro Poblado Jallihuaya, distrito Salcedo, provincia Puno, departamento Puno, ubicado en las siguientes coordenadas geográficas: $15^{\circ} 50$ '36"S $70^{\circ} 01 ' 25^{\prime \prime}$. El proceso implicó la colecta de plantas basadas en sus características botánicas como forma, color de hoja, y tamaño de la planta. La recolección se realizó utilizando prensas botánicas, tijeras y bolsas. Los especímenes fueron depositados en el Herbario de la Universidad Nacional de San Agustín de Arequipa (HUSA), para la correspondiente clasificación taxonómica. La clasificación taxonómica de las especies vegetales recolectadas fue llevada a cabo por una bióloga certificada, basado en las características fenotípicas de cada especie y utilizando una clave taxonómica ${ }^{(21)}$

\section{PREPARACIÓN DEL EXTRACTO}

Luego de la recolección de la especie vegetal, se separaron las hojas y se lavaron con agua destilada. La muestra vegetal (hojas) fueron rápidamente congeladas sumergiéndolas en nitrógeno líquido, las que fueron reducidas a polvo fino usando un mortero. A partir de esta muestra pulverizada se realizó la extracción con metanol, durante 15 minutos a temperatura ambiente $\left(25^{\circ} \mathrm{C}\right)$ utilizando un agitador magnético, luego fue centrifugada a 5000 rpm por cinco minutos y el sobrenadante obtenido fue transferido a un tubo Eppendorf y secado por completo en una estufa a $40^{\circ} \mathrm{C}(22,23)$.

\section{OBTENCIÓN DE LA FRACCIÓN FLAVONOIDE POR CROMATOGRAFÍA}

\section{CROMATOGRAFÍA DE COLUMNA}

La columna fue empacada con silica gel G-60, y la elusión se realizó en gradiente utilizando solventes como acetato de etilo y metanol en las siguientes proporciones: $100 \%$ de acetato de etilo , acetato de etilo metanol 75/25 v/v, acetato de etilo metanol $50 / 50 \mathrm{v} / \mathrm{v}$, metanol $100 \%$, Los eluatos fueron concentrados y secados a temperatura de $40^{\circ} \mathrm{C}{ }^{(24)}$.

\section{CROMATOGRAFÍA EN CAPA FINA}

Se hizo el seguimiento de las fracciones eluidas por cromatografía en capa fina. Se preparó la cámara cromatografica conteniendo fase móvil acetato de etilo/ metanol/ agua (6: 4: 2 v/v). Fueron visualizados con lámpara ultravioleta de $365 \mathrm{~nm}$, se seleccionaron la fracciones de color azul que fueron eluidas con el $100 \%$ de acetato de etilo, seguidamente se realizaron las pruebas biológicas ${ }^{(25)}$.

\section{PACIENTES Y OBTENCIÓN DE MUESTRAS}

El estudio se realizó de acuerdo a las normas éticas concordantes con la Declaración de Helsinki (actualizada al 2013), fue aprobado por el Comité Institucional de Ética de la Investigación de la Universidad Católica de Santa María (UCSM) (Dictamen número 2017-10) y fue obtenido el consentimiento informado por escrito de todos los participantes. Entre los criterios de inclusión se tomó en cuenta a pacientes con artritis de reciente diagnóstico sin tratamiento previo, de sexo femenino y mayores de 18 años. Los criterios de exclusión fueron: pacientes que hayan recibido algún tipo de tratamiento contra la $A R$, con diagnóstico de otras enfermedades autoinmunes y que presenten más de dos comorbilidades. Se obtuvo $15 \mathrm{~mL}$ de sangre venosa de pacientes con artritis reumatoide activa, diagnosticados por médico especialista del Hospital Regional Honorio Delgado de Arequipa.

\section{AISLAMIENTO Y CULTIVO CELULAR}

El aislamiento de los neutrófilos y de los leucocitos mononucleares se realizó utilizando dextrano (3\%) seguido de una centrifugación en gradiente de densidad con Ficoll. Ambos tipos celulares se cultivaron en medio RPMI1640 (Invitrogen) suplementado con $10 \%$ de suero fetal bovino (Gibco) y $1 \%$ con penicilina estreptomicina (Invitrogen) a una densidad de $5 \times 10^{5}$ células $/ \mathrm{ml}$ en placas de cultivo Coastar de 24 pozos a $37^{\circ} \mathrm{C}$ y $5 \%$ de $\mathrm{CO} 2{ }^{(26)}$.

\section{DETERMINACIÓN DE LA PRODUCCIÓN DE ANIÓN SUPERÓXIDO (ENSAYO DE REDUCCIÓN NBT NITROBLUE TETRAZOLIUM)}

Se prepararon tres grupos, el control negativo, que consistió de neutrófilos ( $5 \times 10^{5}$ células /pozo), el control positivo formado por neutrófilos activados con PMA (phorbol myristate acetate) $(150 \mathrm{ng} / \mathrm{mL})$ y los tratamientos formados por neutrófilos activados tratados con diferentes concentraciones de la fracción flavonoide LM8 (60, 120 y $180 \mathrm{ug} / \mathrm{mL}$ ), estos grupos fueron incubados en RPMI 1640 a $37^{\circ} \mathrm{C}$ y fue adicionado $100 \mathrm{uL}$ de solución de NBT (1 
$\mathrm{mg} / \mathrm{mL}$ ) a todos los grupos, para determinar la producción de anión superóxido. Terminada la incubación se realizó una centrifugación a 15000 rpm por dos minutos, luego los sobrenadantes fueron removidos y el "pellet" celular fue lavado dos veces con metanol al $70 \%$ para luego ser solubilizado con 200 uL de DMSO (dimetilsulfóxido) y 200 uL de hidróxido de potasio $(\mathrm{KOH})$ para disolver el precipitado de NBT; esta reacción se llevó a cabo en oscuridad porque la luz puede desnaturalizar el reactivo. La magnitud de reducción del NBT fue cuantificada por espectrofotometría a $570 \mathrm{~nm}^{(27-29)}$.

\section{EVALUACIÓN DE LA EXPRESIÓN GÉNICA}

La evaluación de la expresión génica, se realizó en leucocitos mononucleares los que fueron cultivadas en medio RPMI1640 y separados en tres grupos; un primer grupo de control negativo que consitió de leucocitos mononucleares $\left(5 \times 10^{5} \mathrm{cel} / \mathrm{pozo}\right)$, el control positivo formado por leucocitos mononucleares activados con fitohemaglutinina (PHA) (150 ug/mL) y los tratamientos formados por leucocitos mononucleares activados tratados con la fracción flavonoide LM8, a una concentración de 120 $\mathrm{ug} / \mathrm{mL}^{(26)}$.

\section{EXTRACCIÓN DE RNA YRT-QPCR}

Los niveles de expresión de RNAm fueron medidos por RT-PCR. El RNA total se aisló usando el reactivo TRIzol (ThermoFisher) de acuerdo con las instrucciones del fabricante. La transcripción reversa de RNA a cDNA se hizo utilizando el kit SuperScript III Reverse Transcriptase (ThermoFisher) de acuerdo a las instrucciones del proveedor. Para la preparación de la PCR se utilizó el kit Platinum PCR Supermix (ThermoFisher) y la reacción se realizó en el termociclador Mastercycler pro (Eppendorf) para la amplificación de los genes INF gamma, TNFalfa, IL-17 e IL-8 y como gen house keeping se utilizó la beta actina. La secuencia de los primers utilizados fue la siguiente: INF gamma R: $5{ }^{`}$ - tag ctg ctg gcg aca gtt ca-3`; F: $5^{`}$ - aaa aat aat gca gag cca aat tg -3`; TNF-alfa R: $5^{`}$-ggt gtg ggt gag gag cac at- $3^{`} ; \mathrm{F}: 5^{`}$ - cga gtg aca agc ctg tag C-3`; IL-17 R: 5 - aga ttt agt ccg aaa tga ggc tg $33^{`}$ F: $55^{\prime}$ - tca acc cga ttg tcc acc at- $3^{`}$; IL8 R: $5{ }^{`}-$ ttg gca gcc ttc ctg att tc $-3^{`} F: 5^{`}-$ aac ttc tcc aca acc ctc tg $-3^{\prime}$.

Las condiciones para la amplificación por PCR fueron; desnaturalización $95^{\circ} \mathrm{C}$ por dos minutos seguidos de 40 ciclos de desnaturalización a $95^{\circ} \mathrm{C}$ por 30 segundos, hibridación de $55^{\circ} \mathrm{C}$ por 30 segundos, y extensión a $72^{\circ} \mathrm{C}$ por un minuto, con un volumen total por muestra de $35 \mathrm{uL}$. Para el análisis de la cuantificación comparativa del PCR en tiempo real se usó el método delta delta $\mathrm{Ct}^{\prime}(\Delta \Delta \mathrm{Ct})^{(24)}$

\section{ANÁLISIS ESTADÍSTICO}

Los resultados de anión superóxido fueron analizados por un ANOVA, con una prueba de especificidad de Tukey. Para los resultados de RTqPCR, se realizó el análisis estadístico usando la prueba de $\mathrm{T}$ de student. Todas las pruebas se realizaron por triplicado y se consideró una significancia estadística si $p<0,05$. El análisis se realizó utilizando el programa SPSS ver. 21.

\section{RESULTADOS}

\section{OBTENCIÓN DE LA FRACCIÓN FLAVONOIDE}

Luego de realizar la cromatografía de columna se obtuvieron 40 fracciones a partir del extracto metanólico de Lepechinia meyenii (Walp.) Epling rotuladas con el código LM. Dichas fracciones fueron analizadas por cromatografía en capa fina y visualizadas con luz ultravioleta para la identificación de los flavonoides

En la Figura 1 se muestra el resultado de cromatografía de capa fina correspondiente a un cromatograma representativo de cuatro fracciones, eluidas a partir de la fase móvil acetato de etilo $100 \%$ (LM2,3,4 y 8), donde se aprecia que la fracción LM8 presenta una fluorescencia azul correspondiente a una fracción flavonoide pura sin presencia de otra fluorescencia contaminante. Esta fracción resultó más eficaz para la reducción de especies reactivas de oxígeno y fue utilizada en las siguientes pruebas.

\section{INHIBICIÓN DE LA PRODUCCIÓN DE ANIÓN SUPERÓXIDO}

En la Figura 2 , se muestran los resultados de producción de anión superóxido en neutrófilos activados con PMAy tratados con diferentes concentraciones de la fracción LM8 $(60,120$ y $180 \mathrm{ug} / \mathrm{mL}$ ). Los resultados muestran la concentración

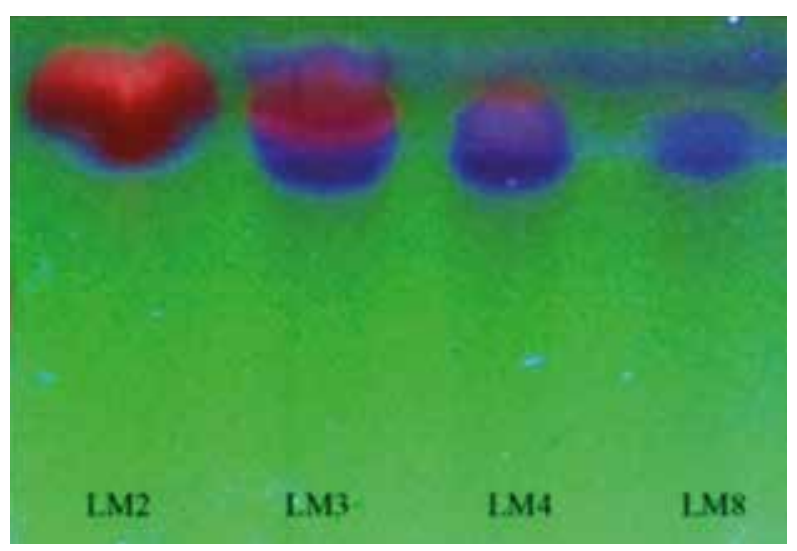

Figura 1. Cromatografía de capa fina de cuatro fracciones obtenidas por separación en cromatografía de columna diluidas con fase móvil acetato de etilo 100\% (LM 2,3,4 y 8). 


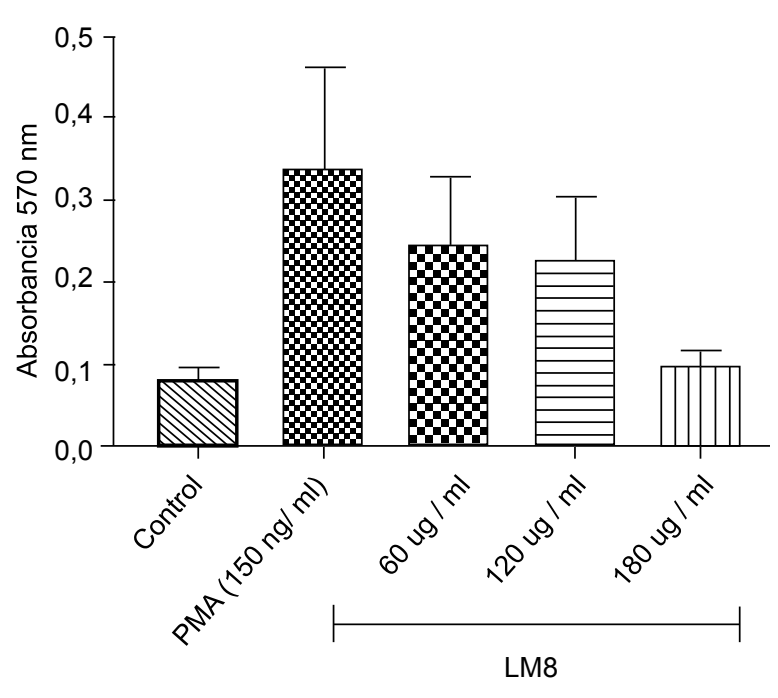

Figura 2. Efecto de la fracción flavonoide LM8 sobre la producción de anión superóxido en neutrófilos activados con phorbol myristate acetate $(P M A)(p<0,008)$

de anión superóxido expresada en absorbancias (Abs), se observa que la fracción LM8 produjo una disminución en la concentración de anión superóxido en un 32,4 \%, 37,6 \% y $70,5 \%$ para las concentraciones de 60,120 y 180 ug/ $\mathrm{mL}$ respectivamente, en una manera dependiente de la concentración, resultando significativo, (ANOVA, $p<0,008$ ) para la concentración de $180 \mathrm{ug} / \mathrm{mL}$.

\section{REGULACIÓN DE LA EXPRESIÓN DE GENES PROINFLAMATORIOS}

En la Figura 3 , se muestra los resultados de la expresión de genes proinflamatorios en leucocitos mononucleares activados con PHA y tratados con la fracción flavonoide LM8. Se observa que la fracción LM8 disminuyó significativamente la expresión de TNFa en un $87,8 \%$ $(p<0,002)$, IL8 en un $47,7 \%(p=0,003)$ y de IL17 en un 50,1\% $(p=0,001)$ respecto a las células tratadas sólo con PHA. Por otro lado, la fracción LM8 provocó un incremento en la expresión de IFNy en un $23,4 \%$ respecto a las células tratadas sólo con PHA $(p=0,11)$.

\section{DISCUSIÓN}

En este estudio se ha purificado y evaluado la actividad antinflamatoria de la fracción flavonoide (LM8), aislada a partir del extracto metanólico de hojas de Lepechinia meyenii (Walp.) Epling (salvia andina) en leucocitos de pacientes con AR. Durante el progreso de la inflamación los neutrófilos participan activamente en las respuestas inflamatorias a través de la liberación de citoquinas y mediadores proinflamatorios ${ }^{(8)}$. Se ha demostrado que mediadores inflamatorios de especies reactivas de oxígeno (ROS), como el anión superóxido (O2-), juegan un rol clave en la patogénesis de muchas enfermedades inflamatorias crónicas y agudas. Igualmente se ha reportado que las especies reactivas de oxígeno estimulan distintas actividades celulares como la secreción de citoquinas y
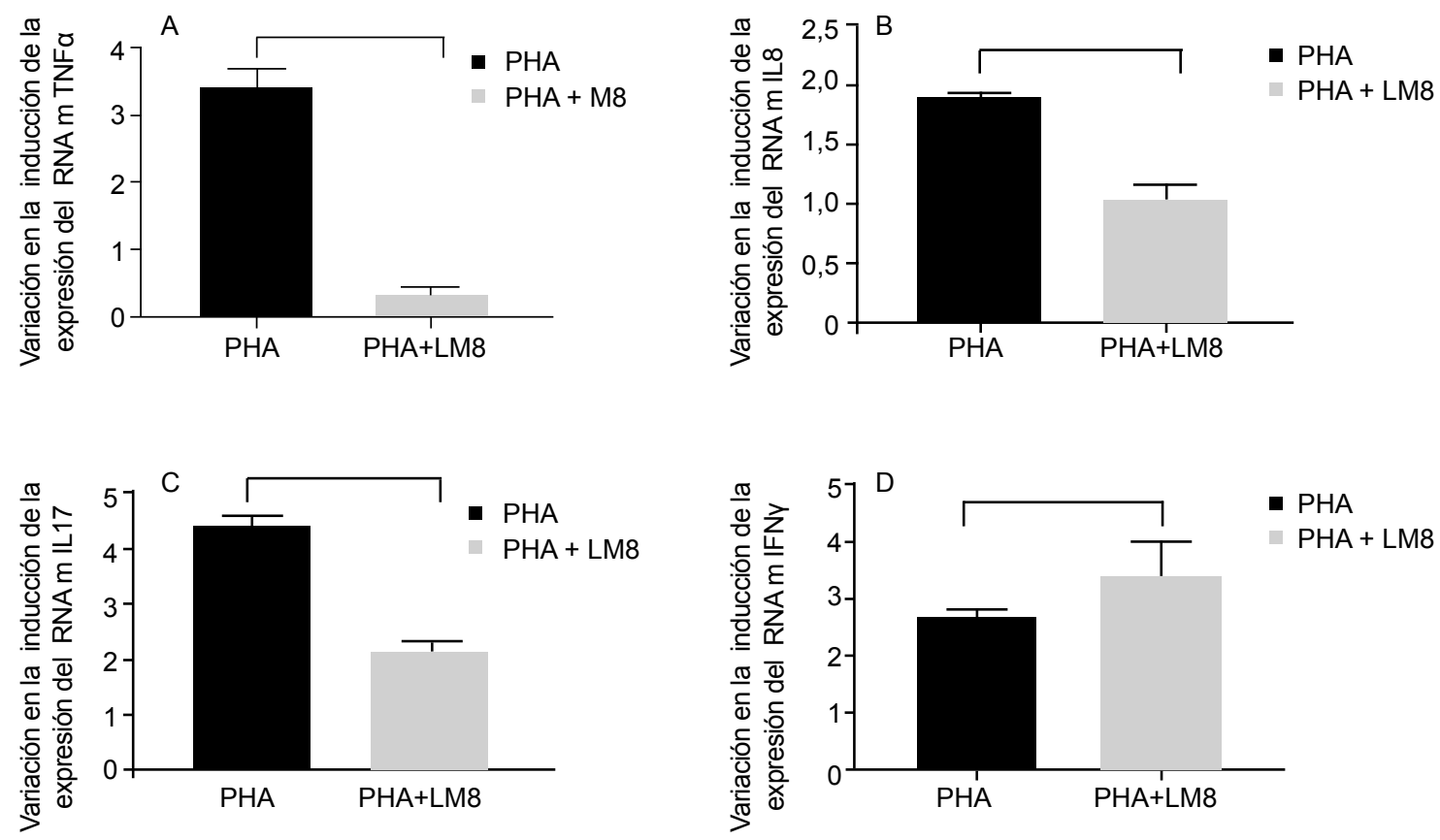

Figura 3. Niveles de expresión del RNAm de genes proinflamatorios: A) TNFa (Valor $p=0,002)$, B) IL8 (Valor $p=0,003$ ), C) IL17 (Valor $p=0,001$ ) y D) IFNy (Valor $p=0,110)$, en leucocitos mononucleares activados con fitohemaglutinina (PHA) y tratadas con la fracción flavonoide LM8 
proliferación celular, mientras que concentraciones elevadas pueden inducir daño y muerte celular ${ }^{(8)}$. Considerando que las especies reactivas de oxígeno como el O2- juegan un rol crítico en un tipo de enfermedad inflamatoria crónica como la artritis reumatoide, se estudió el efecto de la fracción flavonoide LM8, sobre la producción de anión superóxido O2- en neutrófilos activados.

El tratamiento de los neutrófilos con la fracción LM8 redujo la producción de O2- en una manera dependiente de la concentración. Recientes estudios han demostrado que un extracto soluble lipídico de ginsen rojo y de Salvia miltiorrhiza mostraron actividad antiinflamatoria a través de la disminución en la producción de ROS ${ }^{(8)}$. Igualmente se ha reportado que otros componentes derivados de algunas plantas como curcumina, resveratrol e isoflavonas, ejercen actividad antiinflamatoria inhibiendo la producción de ROS, así como la activación de iNOS y COX en diferentes tipos celulares ${ }^{(8)}$.

Las enfermedades inflamatorias se caracterizan entre otros eventos por la producción de cantidades significativas de radicales libres, así como de citoquinas proinflamatorias tales como TNFa, IL1, IL17, IL8, INF gamma ${ }^{(8)}$. Los resultados obtenidos demuestran que la fracción LM8, disminuyó la expresión de TNFa, IL8 e IL17 en células mononucleares activadas con fitohemaglutinina (PHA). Una excesiva producción de citoquinas puede ser inducida por estímulos inflamatorios como el PHA en células mononucleares, lo cual incrementa la respuesta inmune simulando una inflamación ${ }^{(7,8,30,31)}$. En este sentido la inhibición de citoquinas proinflamatorias ha sido identificada como un blanco para terapias antiinflamatorias avalando nuestros resultados de que la fracción LM8 posee una actividad antiinflamatoria inhibiendo la expresión del TNFa e IL8 en células mononucleares ${ }^{(8,30)}$.

Por otro lado, la fracción LM8 incrementó la expresión de interferón gama (IFNy). Del mismo modo, se ha reportado que la quercetina incrementó la producción de IFNy e inhibió la producción de IL4 en células mononucleares de sangre periférica ${ }^{(4)}$. Marchi et al. demostró que el IFNy protege del daño estructural en artritis experimental, regulando el influjo de neutrófilos hacia las articulaciones dañadas (29). Igualmente, en estudios in vitro usando sinoviocitos, el IFNy moduló la producción de TNFa, IL-1 $\beta$ provocando una disminución de IL-8. Algunos reportes indican una disminución en la capacidad fagocítica y producción de ROS después del pre tratamiento con IFNy, mientras que otros estudios demuestran un incremento de estos mediadores inflamatorios, estas diferencias pueden ser explicadas por diferencias en el tiempo de exposición a IFNy, concentración y tipo de célula ${ }^{(29)}$.

Entre las limitaciones de este estudio se indica que los leucocitos sanguíneos obtenidos apartir de los pacientes con artritis reumatoide no tuvieron un basal idéntico de activación en todas las muestras, por lo que se prefirió activar los neutrófilos y leucocitos mononucleares con PMA y PHA respectivamente a una concentración estándar. La fracción flavonoide LM8 fue una de las fracciones que obtuvo un mayor efecto antiinflamatorio pero no fue la única, por limitaciones de tiempo y monetarias no se evaluó las demás fracciones.

No se purificó el principio activo de la fracción LM8, por lo que es poco claro si la actividad de esta fracción es debido a la acción de un solo compuesto o al efecto aditivo o sinérgico de múltiples compuestos de esta fracción. No se elucidó la estructura del principio activo de la fracción LM8 debido a limitaciones de tiempo y monetarias.

En conclusión, los resultados sugieren que la fracción flavonoide LM8 purificada a partir de Lepechinia meyenii (Walp.) Epling tuvo un efecto antiinflamatorio, reduciendo la producción de anión superóxido en neutrófilos activados así como disminuyendo la expresión de citoquinas proinflamatorias tales como TNFa, IL8 e IL17 en leucocitos mononucleares de sangre periférica de pacientes con artritis reumatoidea.

Contribuciones de autoría: CAAC, THS, IVM, RCV, CVG han participado en la concepción y diseño de la investigacion, recolección de resultados, análisis e interpretación de datos,redacción del artículo; revisión crítica del artículo y obtención de financiamiento. CHG ha participado en la revisión crítica del artículo, aprobación de la versión final, aporte de pacientes o material de estudio. SMC, FFR han participado en el procesamiento de resultados.

Fuentes de financiamiento: Fondos internos de investigación de la Universidad Católica de Santa María.

Conflictos de interés: Los autores declaran no tener conflictos de interés.

\section{REFERENCIAS BIBLIOGRÁFICAS}

1. Parejo I, Caprai E, Bastida J, Viladomat $\mathrm{F}$, Jáuregui $\mathrm{O}$, Codina C. Investigation of Lepechinia graveolens for its antioxidant activity and phenolic composition. J Ethnopharmacol. 2004;94(1):175-84.
2. Bussmann R, Sharon D, William L. Brown Center for Plant Genetic Resources. Plantas medicinales de los Andes y la Amazonia : la flora mágica y medicinal del norte del Perú. Centro Willian L. Brown-Jardin Botánico de Missouri 2015.
3. De-la-Cruz H, Vilcapoma G, Zevallos PA. Ethnobotanical study of medicinal plants used by the Andean people of Canta, Lima, Peru. J Ethnopharmacol. 2007; 111(2):284-94. 
4. Castillo Romero PC. Estudio químico y de actividad antioxidante en Lepechinia mayenii Walp.[Tesis Maestria]. Lima: Escuela de Quimica, Pontificia Universidad Católica del Perú; 2004.

5. Chirinos R, Pedreschi R, Rogez H, Larondelle Y, Campos D. Phenolic compound contents and antioxidant activity in plants with nutritional and/or medicinal properties from the Peruvian Andean region. Ind Crops Prod. 2013; 47:145-52.

6. Wang Z, Hwang SH, Guillen Quispe YN, Gonzales Arce PH, Lim SS. Investigation of the antioxidant and aldose reductase inhibitory activities of extracts from Peruvian tea plant infusions. Food Chem. 2017; 231:222-30.

7. Nair MP, Mahajan S, Reynolds JL, Aalinkeel R, Nair H, Schwartz SA, et al. The flavonoid quercetin inhibits proinflammatory cytokine (tumor necrosis factor alpha) gene expression in normal peripheral blood mononuclear cells via modulation of the NF-kappa beta system. Clin Vaccine Immunol. 2006; 13(3):319-28.

8. Bak M-J, Truong VL, Kang H-S, Jun $\mathrm{M}$, Jeong W-S. Anti-inflammatory effect of procyanidins from wild grape (Vitis amurensis) seeds in LPS-induced RAW 264.7 cells. Oxid Med Cell Longev. 2013; (2013):409321. doi: $10.1155 / 2013 / 409321$.

9. Chi L, Gao W, Shu X, Lu X. A natural flavonoid glucoside, icariin, regulates Th17 and alleviates rheumatoid arthritis in a murine model. Mediators Inflamm. 2014; (2014):392062. doi: $10.1155 / 2014 / 392062$.

10. O’Dell JR, Mikuls TR, Taylor TH, Ahluwalia V, Brophy M, Warren SR, et al. Therapies for Active Rheumatoid Arthritis after Methotrexate Failure. N Engl J Med. 2013; 369(4):307-18.

11. McInnes IB, Schett G. The Pathogenesis of Rheumatoid Arthritis. N Engl J Med. 2011; 365(23):2205-19.

12. Miossec P, Korn T, Kuchroo VK. Interleukin-17 and Type 17 Helper T Cells. N Engl J Med. 2009; 361(9):888-98.

13. Dougados M, Soubrier M, Antunez A, Balint P, Balsa A, Buch MH, et al. Prevalence of comorbidities in rheumatoid arthritis and evaluation of their monitoring: results of an international, cross-sectional study (COMORA). Ann Rheum Dis. 2014; 73(1):62-8.

14. Cascão R, Rosário HS, Souto-Carneiro MM, Fonseca JE. Neutrophils in rheumatoid arthritis: More than simple final effectors. Autoimmun Rev. 2010; 9(8):531-5.

15. Brennan FM, McInnes IB. Evidence that cytokines play a role in rheumatoid arthritis. J Clin Invest. 2008; 118(11):3537-45.

16. Güler-Yüksel M, Hoes JN, Bultink IEM, Lems WF. Glucocorticoids, Inflammation and Bone. Calcif Tissue Int. 2018 Jan 8. doi: 10.1007/s00223017-0335-7. [Epub ahead of print]

17. David T, Ling S, Barton A. Genetics of immune-mediated inflammatory diseases. Clin Exp Immunol. 2018. doi: 10.1111/cei.13101.

18. Park SH, Park KH, Oh MH, Kim HH, Choe KI, Kim SR, et al. Anti-oxidative and anti-inflammatory activities of caffeoyl hemiterpene glycosides from Spiraea prunifolia. Phytochemistry. 2013; 96:430-6.

19. Bazylko A, Piwowarski JP, Filipek A, Bonarewicz J, Tomczyk M. In vitro antioxidant and anti-inflammatory activities of extracts from Potentilla recta and its main ellagitannin, agrimoniin. J Ethnopharmacol. 2013; 149(1):222-7.

20. Hammond GB, Fernández ID, Villegas LF, Vaisberg AJ. A survey of traditional medicinal plants from the Callejón de Huaylas, Department of Ancash, Perú. J Ethnopharmacol. 1998; 61(1):17-30.

21. Areche C, Sepúlveda B, Simirgiotis M, Cáceres F, Quispe C, Quispe L, et al. A new mulinane diterpenoid from the cushion shrub Azorella compacta growing in Perú. Pharmacogn Mag. 2014;10(39):543.

22. Jayachandran Nair CV,AhamadS, Khan W, Anjum V, Mathur R. Development and validation of High-performance Thin-layer Chromatography Method for Simultaneous Determination of Polyphenolic Compounds in Medicinal Plants. Pharmacognosy Res. 2017; (Suppl 1):S67-73.

23. Ramos-Escudero F, Muñoz AM, Alvarado-Ortíz C, Alvarado Á, Yáñez JA. Purple Corn (Zea mays L.) Phenolic Compounds Profile and Its Assessment as an Agent Against Oxidative Stress in Isolated Mouse Organs. J Med Food. 2012; 15(2):206-15.
24. Salimikia I, Monsef-esfahani HR, Gohari AR, Salek M. Phytochemical Analysis and Antioxidant Activity of Salvia chloroleuca Aerial Extracts. Iran Red Crescent Med J. 2016; 18(8):812.

25. Altemimi A, Watson DG, Kinsel M, Lightfoot DA. Simultaneous extraction, optimization, and analysis of flavonoids and polyphenols from peach and pumpkin extracts using a TLC-densitometric method. Chem Cent J. 2015; 9:39.

26. Almeida VG, Avelar-Freitas BA, Santos MG, Costa LA, Silva TJ, Pereira WF, et al. Inhibitory effect of the Pseudobrickellia brasiliensis (Spreng) R.M. King \&amp; H. Rob. aqueous extract on human lymphocyte proliferation and IFN- $\gamma$ and TNF- $\alpha$ production in vitro. Brazilian $\mathrm{J}$ Med Biol Res $=$ Rev Bras Pesqui medicas e Biol. 2017; 50(8):e5163.

27. DeChatelet L, Shirley P, Johnston RJ. Effect of phorbol myristate acetate on the oxidative metabolism of human polymorphonuclear leukocytes. Blood. 1976;47(4):545-54.

28. Rook GAW, Steele J, Umar S, Dockrell HM. A simple method for the solubilisation of reduced NBT, and its use as a colorimetric assay for activation of human macrophages by $\gamma$-interferon. J Immunol Methods. 1985; 82(1):161-7.

29. Marchi LF, Sesti-Costa R, Ignacchiti MDC, Chedraoui-Silva S, Mantovani $B$. In vitro activation of mouse neutrophils by recombinant human interferon-gamma: Increased phagocytosis and release of reactive oxygen species and pro-inflammatory cytokines. Int Immunopharmacol. 2014; 18(2):228-35.

30. Jin W, Dong C. IL-17 cytokines in immunity and inflammation. Emerg Microbes Infect. 2013; 2(9): e60.

31. Nowell PC. Phytohemagglutinin: an initiator of mitosis in cultures of normal human leukocytes. Cancer Res. 1960; 20(4):462-6.

Correspondencia: Carlos Arenas Chávez

Dirección: Calle San Salvador 411 Hunter. Arequipa, Perú.

Correo electrónico: carlosarenasaqpe@gmail.com 